\title{
COMUNICAÇÃO, ENSINO E TEMÁTICA AMBIENTAL
}

\section{Escola e meios de comunicação tratam os problemas do meio ambiente de forma a isolá-los dos temas socioeconômicos mais gerais}

A compreensão de que a conjuntura atual da educação brasileira e sua política educacional não têm correspondido aos anseios de uma escola pública de qualidade, revela também a falta de entendimento sobre as relações que existem entre os objetivos da educação como um todo e os objetivos da suposta Educação Ambiental, no que se refere à inserção da temática ambiental no ensino.

Em primeiro lugar, o problema da qualidade de ensino nas escolas públicas no Brasil não deve ser tratado de uma forma isolada do conjunto dos demais problemas sociais. A solução desses problemas passa pela existência de uma sólida democracia, que possa abranger os planos político-econômico e cultural, para que haja efetiva participação do povo na construção do seu destino, como cidadãos conscientes do seu papel histórico, capazes de lutar também por uma política ambiental mais justa. Dessa forma a democratização do saber deve passar por um ensino que trabalhe a possibilidade de construir conhecimentos novos, indissociáveis das realidades sociais. Isto requer uma mudança da visão fragmentada da problemática ambiental por parte dos professores, para uma visão na qual ocorra a interligação e a interdependência entre os fenômenos sociais, econômicos, físicos, políticos e culturais.
Nesse sentido, a questão ambiental pede hoje uma mudança de valores, percepção e conceitos. Algo que se possa contrapor a uma visão de mundo que tem fragmentado a realidade, separando o homem da natureza. A educação através do ensino da temática ambiental deve propiciar reflexão, sobretudo no que se refere à melhoria da qualidade do ensino, quando busca trabalhar conteúdos compatíveis à realidade escolar e de seus alunos. Mas não somente isso, quando também procura refletir sobre a crise ambiental e a formação da cidadania, para compreendê-la e enfrentá-la. "A questão ambiental traz uma contribuição importante para o repensar da própria universidade. (...) A questão ambiental não é o que se convencionou chamar natural, nem social ou cultural. Ela exige um outro paradigma que seja capaz de dar conta da sua complexidade histórico-natural"'.

A realidade, embora dissecada em partes pela departamentalização cartesiana da universidade, constitui-se de um todo complexamente estruturado onde o natural e o

\section{A AUTORA}

\section{Arlêude Bortolozzi}

Geógrafa, Mestre em Educação pela Unicamp - SP. Pesquisadora do Núcleo de Estudos e Pesquisas Ambientais - Unicamp, responsável pela área de Educação Ambiental Formal. 
social não estão dissociados. A sociedade precisa ser estudada na sua complexidade e não como um simples objeto. Nesse sentido, a prática da extensão universitária deve permitir a integração do professor-pesquisador como um agente que busca um novo paradigma para a explicação da realidade, procurando relacionar-se com o novo, com o que é diferente da universidade, ou seja, com a realidade repleta de contradições.

Para alguns autores, o momento atual se caracteriza pela chamada transição dos paradigmas, muito embora em nível institucional e, mais especificamente, no ensino graduado, o que ocorre na prática dos professores é a coexistência dos paradigmas. Entendendo-se por paradigma a própria visão de mundo que, como apontado por Pimentel, reflete-se através da malha de conceituações, teorias, técnicas, metodologias e instrumentos, assim como das crenças e valores existentes na comunidade científica. Pode-se dizer que, na realidade, o que vivemos hoje é a crise do paradigma moderno, o qual, comandando a ciência desde o século $\mathrm{XVI}$, desenvolveu-se quase que exclusivamente nas Ciências Naturais²

\section{CRÍTICA AO POSITIVISMO}

Mas a Ciência que colaborou para a implantação desse mesmo paradigma, fundamentado em nome do progresso e do desenvolvimento tecnológico, vê-se agora chamada a dar respostas e buscar soluções aos problemas ambientais que este mesmo modelo econômico criou. Dessa forma, é preci- so considerar que o novo paradigma, que nesse momento está surgindo, tem sua origem na crítica teórica ao Positivismo ${ }^{3}$, procurando revestir-se do seu caráter tanto científico como social, tentando romper com a fragmentação existente não só entre o homem e a natureza como também entre as Ciências. Torna-se de fundamental importância conhecer as próprias visões de mundo dos educadores ambientais, procurando entender como eles próprios compreendem a questão ambiental, que percepção eles têm da crise ambiental e seus problemas. Enfim, qual concepção eles próprios têm da chamada Educação Ambiental e como essa se reflete em suas ações.

Estudos já realizados por Bortolozzi ${ }^{4}$, com professores que atuam na chamada Educação Ambiental formal, mostram que das 112 atividades analisadas, apenas 13 apresentaram certo nível de integração do ensino, sendo que a maioria dos professores apresenta ainda uma visão dicotômica da realidade, na qual a fragmentação no entendimento da problemática ambiental se mostra como resultado de um imaginário cultural que tem separado não só o homem da natureza como também as Ciências técnicas das Ciências humanas. Isto aponta para a má formação desses profissionais pois, ao serem indagados sobre como acompanhavam a questão ambiental, revelou-se que mais da metade o faziam através dos meios de comunicação de massa tais como TV (noticiários, documentários ambientais, filmes e vídeos) e revistas, em detrimento e não somados aos mecanismos que deveriam ser próprios da educação em todos os níveis,

2. PIMENTEL, M. G. O professor em construção. Campinas: Papirus, 1993. (Coleção Magistério, formação e trabalho pedagógico.)

3. Positivismo é a corrente filosófica que tem como base o racionalismo, a especialização e a compartimentação das Ciências. O filósofo francês Auguste Comte (1798-1857) foi um dos mais conhecidos defensores desta corrente filosófica. (N. Ed.)

4. BORTOLOZZI, A. Educação ambiental e o ensino de Geografia: bacias dos rios Piracicaba, Capivari e Jundiaí. Campinas: Faculdade de Educação da Universidade de Campinas, 1997. 268p. (Tese de Doutorado.) 
como por exemplo: textos, livros paradidáticos, seminários, palestras, cursos, simpósios, encontros e congressos, entre outros.

A crítica que recai principalmente na TV se deve ao fato de que, com relação à questão ambiental, raramente a programação tem ultrapassado os limites de uma abordagem simplista, apresentando uma visão essencialmente naturalista e reducionista dos fenômenos.

Isto porque, ao ignorar uma abordagem socioambiental dos problemas e apresentar temas, envolvendo o meio ambiente de forma genérica como a ecologia, o equilíbrio ecológico e a extinção de espécies, acaba quase sempre por eliminar a explicação sobre as causas dos problemas. Dessa forma, ao se constatar que a TV influencia fortemente o processo de ensinoaprendizagem, no sentido de torná-lo bem mais atraente que a escola, é preciso estar alerta para acompanhar esse movimento de forma crítica e procurar alternativas para integrar as mensagens dos meios de comunicação social com os reais objetivos da educação.

Para que a inserção da temática ambiental no ensino se faça de uma forma integradora, é importante pensar a educação a partir da perspectiva da compreensão de sua complexidade. A escola encontra-se contextualizada em tempo e espaço determinados, nos quais se encontram envolvidos natureza e sociedade: aspectos diferentes que compõem a mesma realidade. A natureza, apesar de ter a sua própria dinâmica, tem sido cada vez mais intensamente alterada pelos processos econômicos, sociais, políticos e culturais. Por isto é que a compreensão do con- ceito de natureza subjacente às relações sociais, como muitas vezes alertado por Gonçalves ${ }^{5}$, é premissa básica para o entendimento das questões do meio ambiente e da produção de um novo saber.

\section{MEIO AMBIENTE E CONTEXTO SOCIAL}

Hoje o que se torna evidente é a necessidade de uma reestruturação do saber que se encontra parcelado, mutilado e disperso, uma vez que, por ter sido herdado do passado pela busca do desenvolvimento técnico e científico, valorizou-se em exagero a especialização em detrimento da compreensão da complexidade e da sua unidade. Essa visão de mundo tem permeado a educação e influenciado o currículo e as práticas escolares fragmentárias.

Como bem ilustrado por Edgar Morin: "As crianças aprendem a História, a Geografia, a Química e a Física dentro de categorias isoladas, sem saber, ao mesmo tempo, que a História sempre se situa dentro de espaços geográficos e que cada paisagem geográfica é fruto de uma história terrestre; sem saber que a Química e a Microfísica têm o mesmo objeto, porém em escalas diferentes. As crianças aprendem a conhecer objetos isolando-os, quando seria preciso, também, recolocá-los em seu meio ambiente para melhor conhecê-los, sabendo que todo ser vivo só pode ser conhecido na sua relação com o meio que o cerca, onde vai buscar energia e organização"6.

A reflexão sobre a educação provocada por Morin é pautada na descoberta da complexidade que se faz presente em qualquer fenômeno da realidade, uma vez que 
essa apresenta uma rede de relações das partes entre si e com o todo, onde tudo está interligado, sujeito/objeto, teoria/prática, particular/geral, local/planetário e objetividade/subjetividade.

Acredito que para a inserção da temática ambiental no processo educativo é preciso esclarecer aos professores, alunos e agentes escolares que a explicação do conhecimento construído a partir da nova realidade, que ora se apresenta cada vez mais degradada, deve apoiar-se num novo paradigma, o qual seja capaz de dar conta da complexidade dos fatos que estão manifestos nas inter-relações entre sujeito-objeto e ambiente.

A questão ambiental, ao envolver a nossa própria vida e a vida do planeta, coloca-se sobre a ordem econômica e política tanto nacional quanto internacionalmente. No nível internacional, a Organização das Nações Unidas - ONU, principalmente através da Unesco, realizou encontros internacionais e pesquisas destinadas a caracterizar a Educação Ambiental. Para a Unesco ${ }^{7}$, a Educação Ambiental pretende a conscientização da inter-relação entre economia, sociedade, política e ecologia. Entre os objetivos destacam-se: a conscientização e a sensibilização para os problemas ambientais, a aquisição de conhecimentos, valores e atitudes voltados à melhoria do meio ambiente. Esta orientação deve favorecer as abordagens globalizantes e interdisciplinares. Com relação ao Brasil, a Constituição traz implícito que o momento é muito especial para uma reflexão crítica sobre a questão ambiental na educação. "Todos têm direito ao meio ambiente ecologicamente bem equilibrado, bem de uso comum do povo e essencial à sadia qualidade de vida, impondo-se, ao Poder Público e à coletividade, o dever de defendê-lo para a presente e futuras gerações". E prossegue no parágrafo primeiro: "Para assegurar a efetividade desse direito incumbe ao Poder Público: Promover a Educação Ambiental em todos os níveis de ensino e a conscientização pública para a preservação do meio ambiente"".

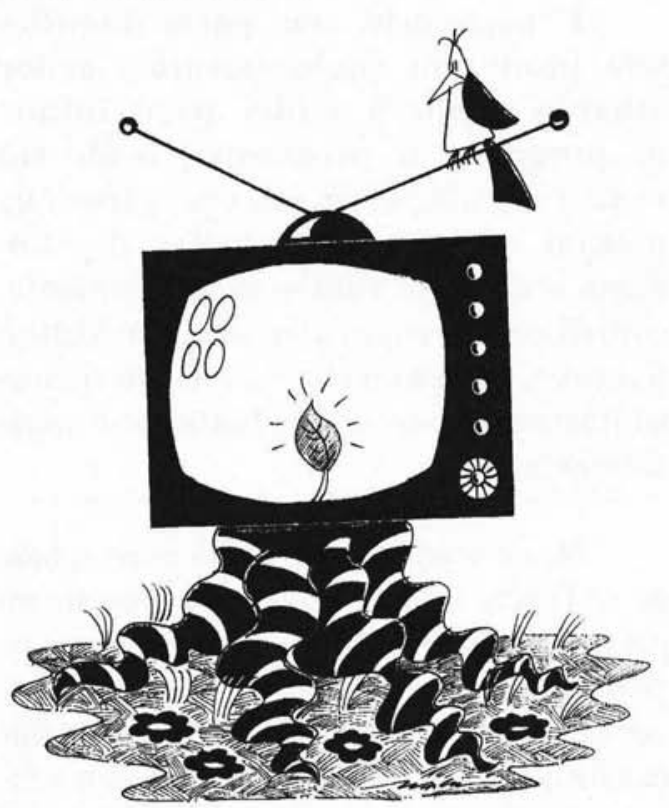

Portanto, algumas questões devem ser colocadas: as medidas geralmente impostas e reconhecidamente reducionistas, em termos educacionais, estão resolvendo os problemas que abarcam a problemática ambiental, permitindo com isso a compreensão da sua complexidade?, que conhecimentos estão envolvidos na chamada Educação Ambiental para todos os níveis de ensino?, que implicações políticas estão imbricadas na organização dessa problemática?

7. UNESCO. La educación ambiental. Las grandes orientaciones de la Conferência de Tibilissi (A educação ambiental. As grandes orientações da Conferência de Tibilissi). Paris, 1985.

8. CONSTITUIÇÃO DA REPÚBLICA FEDERATIVA DO BRASIL. Art. 225, Cap. VI. Do Meio Ambiente, 1988. 
“À Educação Ambiental compete assumir a batalha de oferecer uma concepção de mundo alternativa à difundida pelos meios de comunicação de massa; a propaganda tem, na maioria das vezes, atuado como instrumento formador de mentalidades passivas, induzindo ao consumismo não responsável e servindo exclusivamente a interesses mercantis exacerbados" 9 .

É necessário, por parte daqueles que produzem conhecimentos, maior atuação junto à mídia para influir na produção de programas, tendo em vista a veiculação de valores outros que possam melhorar as relações dos homens entre si e com o meio ambiente, contribuindo, como alertado por Mílton Santos ${ }^{10}$, para que elas se tornem menos solitárias, menos individualistas e mais solidárias.

Nesse sentido, é urgente a necessidade de se buscar formas alternativas que atuem para capacitar e atualizar, principalmente os professores, preparando-os para filtrar e encontrar a essência das mensagens contidas nas imagens que, no cotidiano, passam a fazer parte do imaginário das nossas crianças e jovens, mais suscetíveis a absorverem a ideologia transmitida. O professor precisa aprender a trabalhar adequadamente os recursos audiovisuais que estão presentes nas escolas. O projeto TV Escola pode ser um deles, uma vez que cabe ao professor o papel de mediador entre as várias imagens e conteúdos, devendo, portanto, saber contextualizar os problemas e estabelecer as rela- ções entre as diferentes escalas de espaço e tempo.

O próprio Programa Estadual de Educação Ambiental, ao considerar o Ensino e Meio Ambiente como temas prioritários para o desenvolvimento de um processo educativo que inclua a temática ambiental de forma adequada, reforça o que foi colocado anteriormente e reafirma: "o sistema escolar é um dos canais privilegiados para a difusão e a prática da educação ambiental". Acrescenta ainda que: "A implementação das concepções e diretrizes apontadas nos documentos oficiais pressupõe a práxis da educação entendida como processo de envolvimento das pessoas na construção do saber e não somente na aquisição e execução do conjunto de direitos definidos por especialistas, a partir de ideais de determinados programas e/ou setores da sociedade" 11 .

\section{FORMAÇÃO INTEGRADA E INTEGRADORA}

Com relação à universidade, a importância da Educação Ambiental é inquestionável. Uma formação integrada e integradora deve compreender a problemática ambiental em sua dinâmica histórica. $\mathrm{O}$ universitário deve perceber o seu papel no projeto de Civilização, da razão de ser do ser humano em sua relação com a natureza. A temática ambiental geralmente não penetra o saber universitário. Como comenta Buarque "o único estudo ambiental é aquele da ecologia como categoria de conhecimento, mas não como problema da realidade" 12 .

9. PROGRAMA ESTADUAL DE EDUCAÇÃO AMBIENTAL - Secretaria Estadual do Meio Ambiente - CEA, São Paulo, 1992. p. 10.

10. SANTOS, M. O espaço do cidadão. São Paulo: Nobel, 1987. (Coleção Espaços.)

11. PROGRAMA ESTADUAL DE EDUCAÇÃO AMBIENTAL - Secretaria Estadual do Meio Ambiente - CEA. São Paulo, 1992. p. 6-7.

12. BUARQUE, C. Interação Universidade/Sociedade/Natureza. V Seminário Nacional sobre Universidade e Meio Ambiente. A Universidade, a Conferência 92 e a nova ordem internacional. Textos Básicos. 5 a 10 de abril. Belo Horizonte, 1992. p. 199. 
É preciso repensar sobre o compromisso social da universidade, percebendo que este pode se dar aliando a qualidade do trabalho acadêmico com a visão para uma educação que se preocupe com o desenvolvimento e que procure ajudar a eliminar o processo de exclusão a que estão submetidos alguns setores da nossa sociedade; tomar atitudes que possam avançar numa prática docente compatível com a democracia e a busca de justiça social. Dessa forma, como bem colocado por Buarque, "o compromisso da universidade deve ser com a qualidade, com um saber inédito que possa ir além do saber tradicional. (....) Lamentavelmente nem todos os professores e alunos das universidades têm atualmente o sentido deste compromisso. Ensinam repetitivamente o pensamento antigo, sem descobrir novos temas, nem a humanidade que existe ao redor" 13 .

Ao optar por uma formação de especialistas na graduação, a universidade não prioriza, muitas vezes, o seu papel de colaboradora da melhoria da qualidade do ensino secundário. Apesar de poder contar com especialistas em quase todas as áreas, tem sido muito difícil sensibilizar a comunidade universitária no sentido da mobilização de diferentes competências para se pensar a formação do professor do Ensino Médio.

As instituições, em nível da graduação, deveriam procurar trabalhar a temática ambiental nos diferentes ramos do saber, de forma coerente com a busca da melhoria da qualidade de vida para todos.

Muito embora tenhamos a consciência de que a escola não deve ser a única responsável pela formação da consciência ambien- tal, porque isto cabe também à sociedade como um todo, ela representa um estágio importantíssimo na formação da cidadania.

A escola deve preparar seus educandos para uma formação integral que os leve a um exercício participativo, fundamental para a busca dos seus direitos. No enfoque ambiental o direito a uma boa qualidade de vida me parece inalienável.

A abordagem de temas ambientais que contemplem desde fenômenos locais até os mais globais e o entendimento das suas relações, considerando para tanto suas diferentes escalas, pode permitir uma compreensão mais globalizadora da realidade, passando a exigir um trabalho interdisciplinar. Por outro lado, os métodos e recursos pedagógicos, principalmente os audiovisuais, exigidos por um currículo ambientalizado e por um trabalho interdisciplinar nas escolas, deverão contribuir para uma atuação maior quanto ao cuidado no gerenciamento do meio ambiente circundante.

Nesse sentido é que acredito na possibilidade de a questão ambiental vir a constituirse num elemento catalizador para as discussões que possam levar a uma renovação do ensino universitário e da sua participação nos meios de comunicação social. Quando se pensa na formação dos professores que deverão refletir sobre a organização espacial do Brasil e do mundo e na sua crescente degradação ambiental, uma inquietação se coloca: quem serão os atores sociais que, já nesse despontar do novo século, deverão estar dando respostas aos problemas pertinentes à organização social e política do nosso país? 
Resumo: Este artigo tem como objetivo buscar a integração entre a questão ambiental e o sistema educacional, visando à aproximação da universidade com o ensino de primeiro e segundo graus ou, respectivamente, ensino fundamental e médio. Reflete sobre as possiveis formas de melhorar a qualidade do ensino relacionado à temática ambiental. Considera, sobretudo, a relação do trabalho em sala de aula e as informações adquiridas através dos meios de comunicação, inclusive o Projeto TV Escola, destacando a necessidade de se capacitar professores para uma visão integradora da problemática ambiental, na busca de soluções para os problemas ambientais da comunidade em sua complexidade socioeconômica e política.

Palavras-chave: Educação Ambiental, cidadania, complexidade do conhecimento
Abstract: This article aims at searching for the integration between the environmental matter and the educational system, hoping to approximate the university to elementary and high school teaching, or, fundamental and medium teaching, respectively. It reflects on the possible manners through which improve the quality of teaching relative to the environmental theme. It considers, most of all, including the TV School Project, emphasizing the need to capacitate teachers for an integrating view on the environmental problematic, searching for solutions for community environmental problems considering their socioeconomic and political complexities.

Key words: Environmental Education, citizenship, knowledge complexity 